\title{
Smart Water for Enhanced Oil Recovery by Nano-Filtration
}

Remya Ravindran Nair*, Evgenia Protasova and Torleiv Bilstad

Department of Mathematics and Natural Sciences, University of Stavanger, Kjell Arholmsgate 41, 4036 Stavanger, Norway

\begin{abstract}
Chemistry of injected water can modify the wettability behaviour of carbonate reservoirs. Wettability modification towards more water-wet reservoir rocks results in increased oil production. Smart water production by selective ionic water content is a major developing area in current enhanced oil recovery (EOR). Technical limitations for smart water production for EOR using seawater as feed for membranes are described in this paper. Desired characteristics of smart water for injection into carbonate reservoirs are low $\mathrm{Na}^{+}$and $\mathrm{Cl}^{-}$and high divalent ion concentrations. Wettability alteration by smart water occurs due to symbiotic behaviour of $\mathrm{Ca}^{2+}, \mathrm{SO}_{4}{ }^{2-}$ and $\mathrm{Mg}^{2+}$ ions and the carboxylic material of the reservoir rock surface.

Nano-filtration (NF) and Reverse Osmosis (RO) membranes were used for ion separation experiments. Retentate from NF contains the main constituents of smart water. Membrane performance was evaluated in terms of rejection under varying feed compositions and pressures. An analysis of general approaches for water injection processes from seawater is discussed. This paper delivers an economic framework for evaluation of the water injection process by including major technical and economical elements.

Main criteria considered in this research were how to decrease monovalent ion rejection. This was achieved by increasing divalent ion concentration by spiking feed water with selected chemicals. Results showed that a decrease in retention of monovalent ions was achieved by increasing multivalent ion concentration in the feed. A challenge of smart water production is the high dissolved solids content (TDS) in retentate from NF. Three options to dilute the retentate were evaluated; i.e., combinations of NF and RO, MSFD and fresh water. The most feasible process is a combination of $\mathrm{NF}$ and $\mathrm{RO}$, with an energy consumption of $3.8 \mathrm{kWh} / \mathrm{m}^{3}$.
\end{abstract}

Keywords: Smart water; Nano-filtration; Enhanced oil recovery; Seawater; Reverse osmosis

\section{Introduction}

A comparatively new EOR method for chalk reservoirs, and most probably applicable for other carbonates, consists of altering wettability by injecting smart water. Smart water floods hydrocarbon reservoirs after changing ionic composition of seawater. Wettability is an important factor controlling the fluid distribution in a reservoir. Injected smart water alters the oil-water-rock equilibrium, modifies wetting properties of the reservoir system, the capillary pressure as well as water and oil permeability. Due to changing equilibrium conditions of reservoirs, smart water displaces oil from rocks thereby increasing oil recovery [1]. High divalent and low monovalent ion concentrations are recommended for smart water. Increased interest in EOR by smart water is due to more- than- expected oil recovery from Ekofisk chalk reservoir in the North Sea. The chalk reservoir of Ekofisk has been flooded with seawater for about 25 years with remarkable success. The Ekofisk reservoir is preferentially oil-wet.

The main parameters which influenced the success of smart water injection of Ekofisk were:

1. High reservoir temperature of $130^{\circ} \mathrm{C}$ which is excellent for smart water to act as a wettability modifier.

2. Highly fractured reservoir which allows the injected water to imbibe from the fractures into the matrix blocks.

Both oil and initial formation water (VB) will be displaced into the fractures and transported through the fracture system to the producers. Low matrix permeability of 1-2 milli Darcy (mD) [1].

Tertiary or EOR technologies are introduced when injected fluids are appearing in significant amount in production wells, making oil production less economical. Implementation of EOR is interrelated to the oil price and overall economics. EOR is capital and resource intensive primarily due to high injecting costs.

Primary and secondary recovery target mobile oil in the reservoir whereas EOR targets immobile oil that cannot be easily recovered due to capillary and viscous forces [2]. Timing for implementing EOR is important. Oil production are classified according to Figure 1.

\section{Wettability}

Wettability is the tendency of a fluid to spread on or adhere to a solid surface in the presence of other immiscible fluids [3]. Wettability controls the flow, location and distribution of fluids in the reservoir [3] and refers to the wetting preference of the rock and does not refer to the fluid that is in contact with the rock.

In a CBR system wettability is a measure of rock preference for either oil or water.

If the rock is water-wet, there is a tendency of water to occupy the small pores and to contact the majority of the rock surface.

If the rock is oil-wet, the rock is preferentially in contact with the oil which will occupy the small pores and contact the majority of the rock

Corresponding author: Remya Ravindran Nair, Department of Mathematics and Natural Sciences, University of Stavanger, Norway, Tel: +47-96816575; E-mail: remya.nair@uis.no

Receive January 08, 2016; Accepted March 24, 2016; Published March 31, 2016

Citation: Nair RR, Protasova E, Bilstad T (2016) Smart Water for Enhanced Oi Recovery by Nano-Filtration. J Pet Environ Biotechnol 7: 273. doi:10.4172/21577463.1000273

Copyright: $\odot 2016$ Nair RR, et al. This is an open-access article distributed under the terms of the Creative Commons Attribution License, which permits unrestricted use, distribution, and reproduction in any medium, provided the original author and source are credited. 
Citation: Nair RR, Protasova E, Bilstad T (2016) Smart Water for Enhanced Oil Recovery by Nano-Filtration. J Pet Environ Biotechnol 7: 273. doi:10.4172/2157-7463.1000273

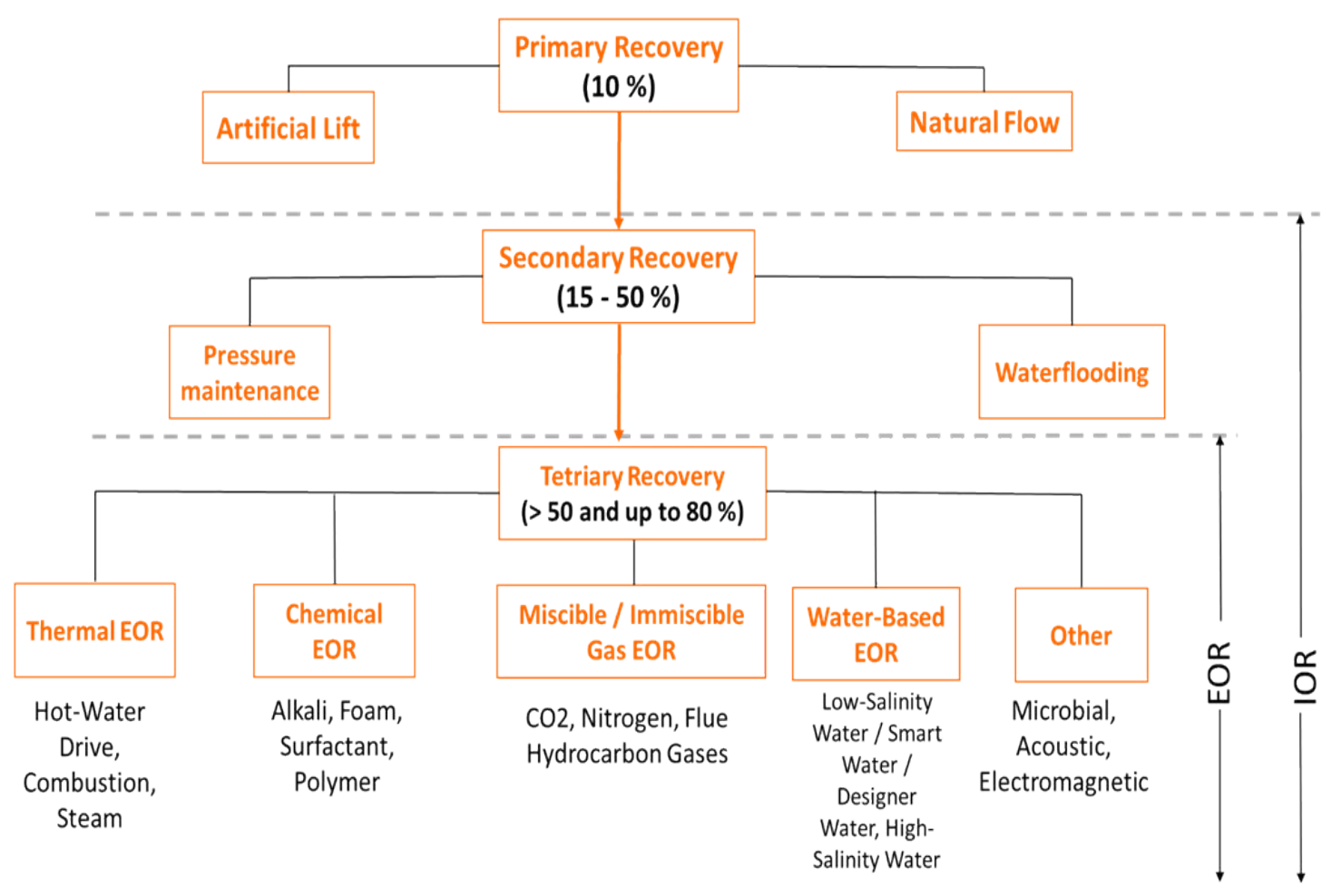

Figure 1: Oil recovery mechanism.

surface. The wettability of a rock surface is dependent on the thickness of the water film between the rock surface and the crude oil. The main properties related to wettability are:

a. The system is stable and remains water-wet with very thick water film.

b. The film will break if it is unstable, resulting in the adsorption of polar components onto the rock surface.

c. The stability of the water film depends on the extent of the disjoining pressure, which results from the intermolecular or inter-ionic forces.

The main interactions between crude oil/brine/rock (CBR) are polar interactions, surface precipitation, acid/base interactions as well as ion-binding or specific interactions between charged sites and higher valence ions. For ion-bonding mechanism, di- and multivalent ions can bind at both oil and solid-water interfaces and/or bridge between them [4].

\section{Smart water}

Smart water is produced by adjusting the ionic composition of seawater (SW) and improves the water wetness of chalk. Salinities of $6,000-28,000 \mathrm{ppm}$ are most suitable as smart water. Advantages of smart water injection include higher ultimate oil recovery with low added investment, assuming that a water-flooding infrastructure is already in place. Injection of smart water may also be performed during early life cycles of reservoirs. Smart water production is comparatively cheap, environmental friendly and without use of chemicals [5]. The effect of smart water on the oil-wet reservoir is shown in Figure 2.

Figure 2 shows the recovery factor when smart water from seawater

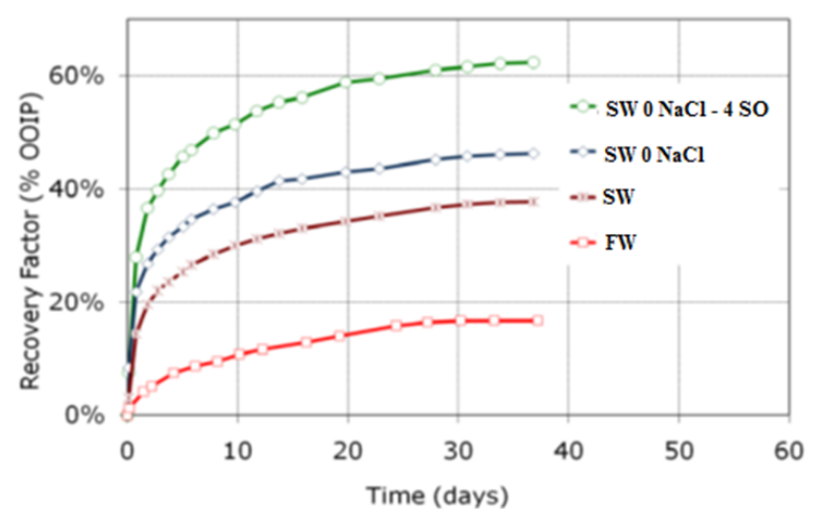

Figure 2: Effect of smart water on oil-wet reservoir [6].

depleted in $\mathrm{NaCl}$ and spiked with 4 times sulphate of normal seawater (SW $0 \mathrm{NaCl}-4 \mathrm{SO}_{4}$ ), normal seawater (SW), formation water (VB) and seawater with no $\mathrm{NaCl}(\mathrm{SW} 0 \mathrm{NaCl})$, is injected into the reservoir. The mechanism of enhanced oil recovery by smart water is altering the wetting behavior of the CBR-system. The physical and chemical wettability alterations take place at the rock surface and determine the efficiency of recovery.

Oil - wet or mixed - wet characteristics of carbonate reservoirs are due to adsorption of negatively charged carboxylic groups of oil to the positively charged calcium carbonate surfaces [6].

For both sandstone and carbonates reservoirs, oil recovery by injecting original formation water was different from smart water. 
Formation water has for millenniums been in equilibrium with the CBR-system prior to water injection [1].

\section{Mechanism for wettability alteration}

Based on a number of experiments done on carbonates, wettability alterations were proposed to be a crucial reason for improving oil recovery. A schematic model of the chemical mechanism for wettability modification is presented in Figure 3 and explained with bullet points below [1].

The access of potentially determining ions $\left(\mathrm{SO}_{4}^{2-}, \mathrm{Ca}^{2+}\right.$ and $\left.\mathrm{Mg}^{2+}\right)$ to the calcite surface is affected by the presence and concentration of non-active monovalent ions in the double layer [6]. Monovalent ions create a double layer close to the positively charged carbonate surface, preventing the adsorption of sulphate to the surface (Figure 3). High $\mathrm{Na}^{+}$and $\mathrm{Cl}^{-}$concentrations have an adverse effect on oil recovery.

It is confirmed that sulphate acts as a strong potential determining ion towards calcium carbonate surface. Sulphate is able to change the zeta potential of carbonate surface from positive to negative at slightly basic $\mathrm{pH}$ [7]. At temperatures below $100^{\circ} \mathrm{C}$, seawater depleted in $\mathrm{Na}^{+}$ and $\mathrm{Cl}^{-}$and spiked with $\mathrm{SO}_{4}^{2-}$ seemed the best composition of smart water. Oil recovery increased from 37 to $62 \%$ of OOIP by spiking the monovalent depleted seawater with 4-times sulphate concentration of normal SW [1].

As smart water is injected into the fractured carbonate reservoir, sulphate ions will adsorb onto the positively charged calcite surface and lower the net positive charge. Concentrations of $\mathrm{Ca}^{2+}$ close to the rock surface is increased due to less electrostatic repulsion, and $\mathrm{Ca}^{2+}$ binds to the negatively charged carboxylic oil groups which are then released from the rock surface. Both concentrations of $\mathrm{SO}_{4}{ }^{2-}$ and $\mathrm{Ca}^{2+}$ at the carbonate surface increase as temperature increases [6]. Presence of trivalent anions (phosphate, borate) may induce surface ion exchange [8].

\section{Carbonate reservoirs}

Carbonate rocks which include chalk and limestone comprise more than half of the hydrocarbon reserves in the world. Around $60 \%$ of the world's oil and more than $40 \%$ of gas reserves occupy carbonate reservoirs. Most carbonate reservoirs consist of high-permeability fractures and a low permeability matrix medium. This dual state makes carbonate reservoirs extremely difficult to recover oil. The matrix has the main oil storage capacity, whereas the fractures provide the principal flow paths [9]. Figure 4 shows a microscopic image of a highly porous chalk reservoir.
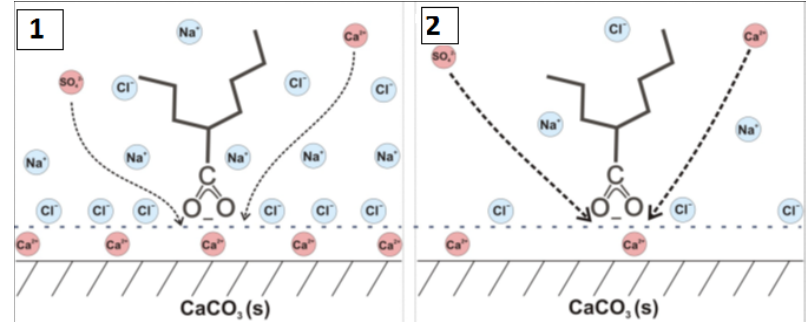

Figure 3: Model of wettability alteration induced by smart water in carbonate reservoirs [6].

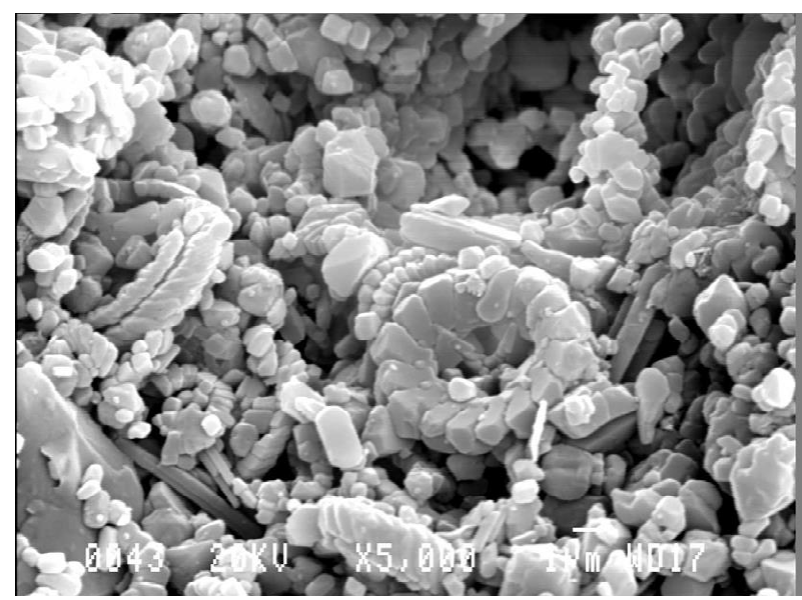

Figure 4: High porosity Coccolith chalk [1].

\section{Smart water production}

Adequate water quality and quantity for enhancing oil production vary between reservoirs. Whether it is technically and economically possible to accomplish proper water quality must be evaluated. In this experiment, volume of water used for injection by Marathon Oil at Brae Alpha field is taken as reference for calculations. As model for water injection, Brae Alpha field with 20,000 bpd (barrels per day) is used [10].

Smart water for enhanced oil recovery in chalk reservoirs are produced mainly by seawater desalination. Methods for desalination of seawater are categorised into 1) Membrane based and 2) Thermal based. RO and NF are pressure driven membrane based desalination technologies commercially available. Thermal based technologies include Thermo compression distillation (TCD), Mechanical vapour compression (MVC), Multi- effect distillation (MED), as well as Multistage flash Distillation (MSFD). MSFD will be considered in this paper for economic analysis calculations. Significant drivers to be considered during an economic analysis are:

a) Availability of water resources; quality, quantity and proximity to final users.

b) Environmental impacts and energy cost.

c) Maintenance.

Desalination technology and plant capacity. As mentioned before, the main requirement for smart water composition is low concentration of the monovalent ions $\mathrm{Na}^{+}$and $\mathrm{Cl}$, and high concentration of the divalent ions $\mathrm{Ca}^{2+}, \mathrm{Mg}^{2+}$ and $\mathrm{SO}_{4}^{2-}$. This requirement can be satisfied by adding proper chemicals to desalinated seawater or use seawater as feed to NF:

Fresh water from land + Chemicals, RO permeate + Chemicals, Multistage Flash Distillation (MSFD) + Chemicals, for Nanofiltration.

Footprint and weight of equipment are major challenges on offshore platforms. An analysis of necessary process units, power consumption and economics for producing smart water must be estimated for choosing the optimal method.

\section{Membranes}

Membranes work on the principle of particle separation and the 
unique feature is their effective pore size. Pore size affects the minimum size of particle that can be rejected by membranes. Schematic of a nanofiltration membrane process is shown in Figure 5.

RO deals with separation of ionic size particles in the range of $0.001 \mathrm{micron}$ or less and molecular weight of $200 \mathrm{~g} / \mathrm{mole}$ or less. NF membrane is between RO and UF separation range and is suitable for the separation of particles in the range of 0.01 micron to 0.001 micron with a MW of $200 \mathrm{~g} / \mathrm{mole}$ and above [11].

Nanofiltration membranes: Water flux and ion rejection are the main performance indicators of nano-filtration. NF performance is affected by: Pore size, material hydrophobicity and chemical structure of membrane are key surface characteristics which affect retention, fouling and flux.

Electro kinetics characteristics such as membrane surface and zeta potential affect the transport mechanism and can be changed by $\mathrm{pH}$ of the system [12].

\section{Operating parameters}

The most important operating parameters affecting the performance of NF process are:

Pressure: Effective driving pressure is the difference between applied hydraulic pressure and the osmotic pressure applied on the membrane by the solutes. NF membranes usually provide good separation at net pressures of 8 bars or higher.

Temperature: An increase in temperature leads to reduction in viscosity and eventually increases flux.

Cross flow velocity: Increasing cross flow velocity removes fouling layer from membrane surface and increases flux.

pH: $\mathrm{pH}$ is a critical parameter which affects electro kinetics and nanofiltration performance.

- NF membranes are negatively charged at neutral or higher $\mathrm{pH}$ but lose their charge at acidic $\mathrm{pH}$.

- Change in solubility of ions at different $\mathrm{pH}$ regimes cause different rejection rate and change the dissociation state of membranes [13].

Salinity: With an increase in ionic strength of surrounding liquid, the effective radius of charged pore will also increase. Rejection of monovalent ions will decrease when their concentration in feed solution increases. The shield effect of membrane charge also increases as ionic strength of feed solution increases [12].

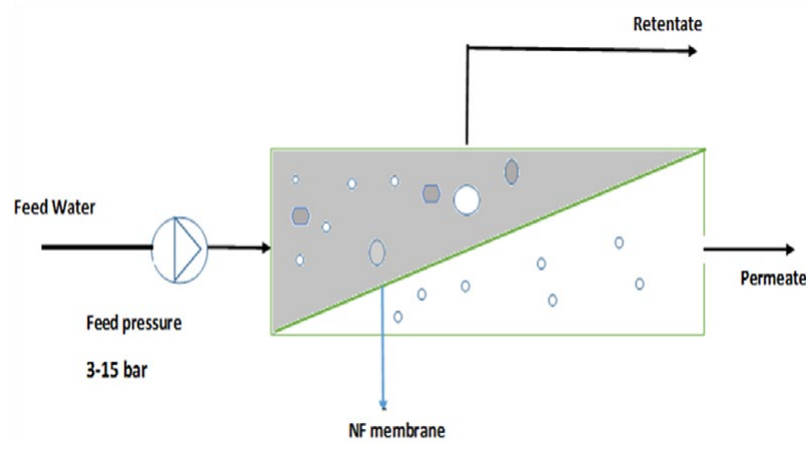

Figure 5: Schematic of a NF membrane process.
Transport mechanism in NF membranes: Ions with charge similar to membranes are rejected at the membrane surface due to Donnan exclusion, in order to satisfy the electro neutrality condition. However, an equivalent number of counter ions is also retained. The Donnan effect leads to differences in rejection according to ionic charges. Multivalent ions such as $\mathrm{SO}_{4}^{2-}$ have a higher rejection in NF compared to monovalent ions since the charge interactions are larger and co-ions are efficiently retained [14]. The Donnan effect is dependent on salt concentrations, valence of co-ions, surface charge of the membrane and valence of counter- ions [15].

Depending on Sieving effect or Stearic hindrance the membranes reject solutes with larger molecular weight than the defined molecular weight cut-off of the membrane. Solutes with lower molecular weight flows as permeate through the membrane [14].

Sieving effects are applied for the retention of ions and the sizes of hydrated ion radius are considered in water solutions. Stokes radius (Stoke-Einstein Relationship) and hydration energy are expected to influence retention of ions. Rejection of solutes increases with increasing stokes radius and hydration energy [16]. Additional energy is required to remove ions with higher hydration energy and permeate it through the NF pores compared with ions having lower hydration energy. Thus, hydration energy can affect retention $[17,18]$. Table 1 shows values for stokes radius and hydration energy of ions in seawater.

Negative rejections of ions in pressure-driven NF membrane processes is well explained according to Yaroshchuk [19]. This occurs due to increased concentration of an ion in the membrane phase. Negative rejections can also happen for ions with decreased concentration in the membrane phase. This is due to the acceleration of such ions into permeate by strong rejections of other components in the feed. This phenomenon is most common for single-charge ions accompanied by predominant amounts of ions of higher valence of the same charge.

\section{Experimental Procedures}

1. All experiments were done at the University of Stavanger, Norway. Seawater used were filtered prior to membrane seperation to avoid fouling, plugging and bacterial growth.

2. Two types of membranes were used with normal seawater (NSW) as feed, NANO SW - 2540 and SW 30- 2540 (RO) at low transmembrane pressures (Figure 6). Use of RO membrane SW 30- 2540 was for producing permeate for dilution of NF retentate or to produce smart water by adding chemicals to RO permeate.

3. Main objective of this research was to decrease rejection of monovalent ions and increase rejection of divalent ions. In order to attain the specified ion composition of low monovalent

\begin{tabular}{|c|c|c|}
\hline Ion & Stoke Radius $(\mathbf{n m})$ & Hydration Energy $\left(\mathrm{KJ}^{\prime} / \mathbf{m o l}^{-1}\right)$ \\
\hline $\mathrm{Na}^{+}$ & 0.184 & 407 \\
\hline $\mathrm{Cl}^{-}$ & 0.121 & 376 \\
\hline $\mathrm{F}^{-}$ & 0.117 & 515 \\
\hline $\mathrm{NO}_{3}^{-}$ & 0.128 & 329 \\
\hline $\mathrm{SO}_{4}{ }^{2-}$ & 0.231 & 1138 \\
\hline $\mathrm{Ca}^{2+}$ & 0.310 & 1584 \\
\hline $\mathrm{Mg}^{2+}$ & 0.341 & 2018 \\
\hline
\end{tabular}

Table 1: Stokes radius and hydration energy of ions [18]. 
and two to three times increased concentration of divalent ions compared to normal seawater, spiking the feed normal seawater with these particular ions were also done. Hence, normal seawater was spiked with sulphate, calcium, magnesium and phosphate. Ions were analysed using ion chromatography.

4. Filtered seawater passed through the membrane at varying pressures. For NANO SW-2540, the pressures were from 6 to 16 bar. Schematic of process flow of the experiment is shown in Figure 7.

\section{Results and Discussion}

Smart water for injection in chalk reservoirs may be produced in four different ways. The optimal technique is chosen by calculating power consumed by each technique in Figure 8. Calculations were with reference to 20,000 bpd or $108 \mathrm{~m}^{3} / \mathrm{h}$ used at Brae Alpha platform [10]. General information regarding Brae A, B and C fields in the North Sea is given in Table 2.

Efficiency of pump is assumed at $60 \%$. Flow rates used for power calculations are based on experiments at the University of Stavanger.

From Figure 8 it is obvious that fresh water from land $(6.94 \mathrm{KWh} /$ $\mathrm{m}^{3}$ ) is the most economical process. But due to the socio-environmental aspects and availability of fresh water, NF can be chosen as the most viable process in terms of energy consumption $\left(47.5 \mathrm{KWh} / \mathrm{m}^{3}\right)$ with no chemicals added. The energy consumed by RO $\left(1100 \mathrm{KWh} / \mathrm{m}^{3}\right)$ can be decreased by $50 \%$ if energy recovery is applied; i.e., $50 \%$ of the energy required for feed pump is recovered from the retentate flow pressure. Multi Stage Flash Distillation (MSFD) has the highest power

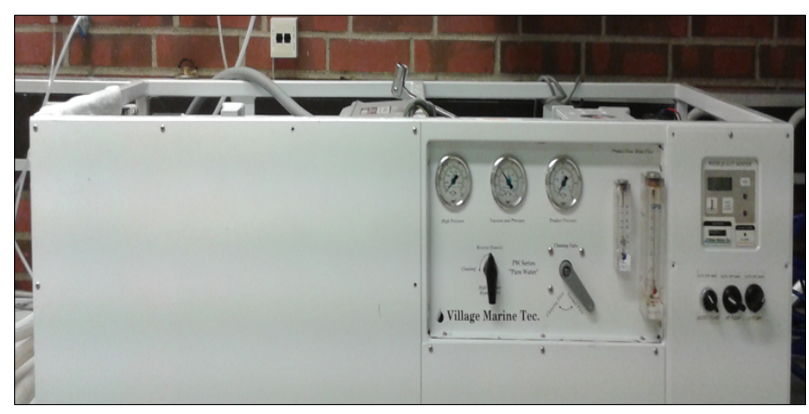

Figure 6: Membrane pilot unit.

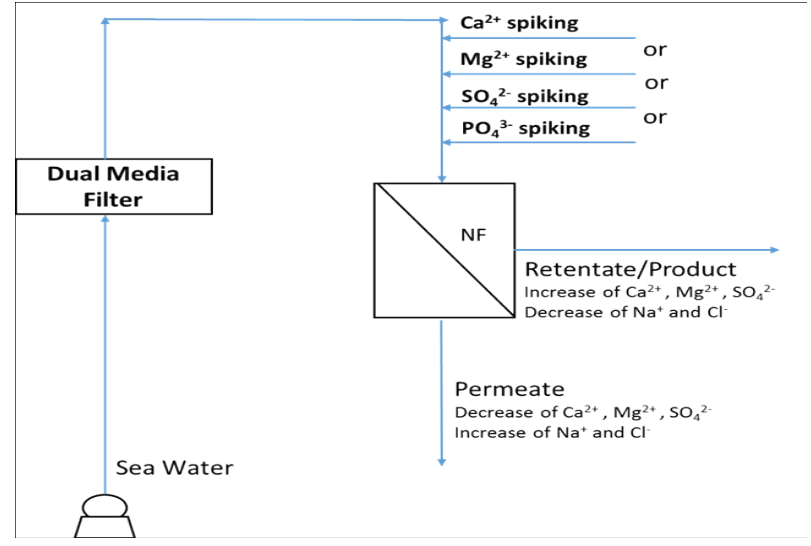

Figure 7: Process flow of experiments.

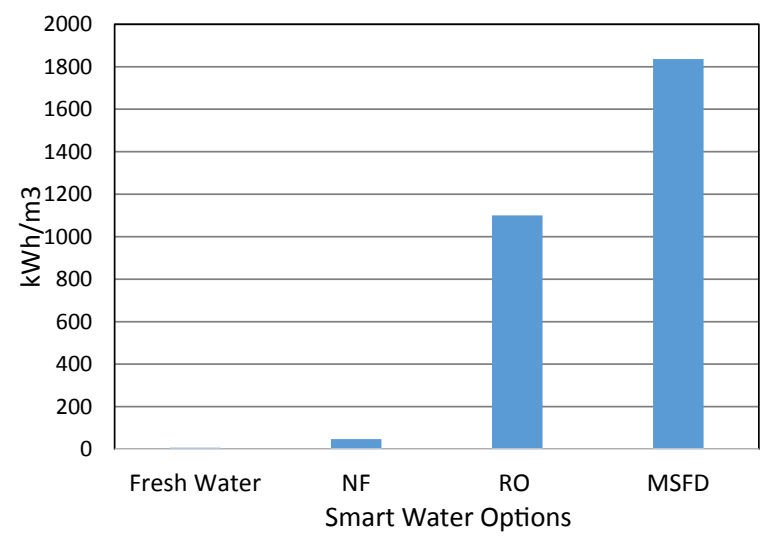

Figure 8: Power consumption.

consumption making it the least suitable option.

Since water injection is usually performed offshore, the space and weight of the process units are important. Calculations were done to estimate the number of 2540 membrane elements required for NF and RO. Total number of elements used according to the permeate flows from the experiments is shown in Table 3. Membrane cost considered are for the membranes used for the experiments, i.e., 726 USD for a reverse osmosis membrane and 335 USD for a nanofiltration membrane.

Table 3 confirms that using NF for smart water production is the chosen option considering space (120 elements in the platform), weight, and energy consumption when compared to RO.

\section{Individual ion behavior on membranes}

Ionic analysis were performed from samples of feed, permeate and retentate collected at various flux values and analysed using ion chromatography. The rejection of individual ions with normal seawater as feed is shown in Figure 9.

Figure 9 shows that separation using NF membranes are selective. This is due to sieving through the nano-sized pores and the Donnan exclusion caused by the NF membranes surface charge.

Ionic rejection at increasing pressure is proportional for all ions except $\mathrm{SO}_{4}^{2-}$. Small size of ions and low hydration energy of $\mathrm{Na}^{+}$and $\mathrm{Cl}^{-}$compared to $\mathrm{SO}_{4}{ }^{2-}$ lead to monovalent ions permeating easily even at low pressures; i.e., diffusion controlled [16]. The retention of chloride is low in order to satisfy the charge equilibrium conditions, balancing high permeation of counter ion $\mathrm{Na}^{+}$and high retention of co-ion $\mathrm{SO}_{4}^{2-}$. However, the charge of the divalent cations produces a strong attractive force towards the negatively charged membrane and hence the retention is not as high as $\mathrm{SO}_{4}^{2-}$ for $\mathrm{Mg}^{2+}$ and $\mathrm{Ca}^{2+}$ (Figure 9).

The cations $\mathrm{Mg}^{2+}$ and $\mathrm{Ca}^{2+}$ are retained based on relatively larger sizes [16]. Rejection of $\mathrm{Ca}^{2+}$ ions is lower than $\mathrm{Mg}^{2+}$ ions, which is explained by lower Stoke radius of $\mathrm{Ca}^{2+}$ as well as lower hydration energy (Table 1 ). $\mathrm{Ca}^{2+}$ also has higher affinity towards the negatively charged membrane. Donnan exclusion theory also explains lower rejection of $\mathrm{Ca}^{2+}$. The negatively charged membrane will repel divalent anions such as $\mathrm{SO}_{4}^{2-}$ which results in less retention of counter ions such as $\mathrm{Ca}^{2+}$ [17]. The relationship between hydration energy and rejection of individual ions in seawater is shown in Figure 10.

\section{Effect of feed ion concentration on membrane properties}

Concentration of sulphate, calcium, magnesium and two types of 
Citation: Nair RR, Protasova E, Bilstad T (2016) Smart Water for Enhanced Oil Recovery by Nano-Filtration. J Pet Environ Biotechnol 7: 273. doi:10.4172/2157-7463.1000273

Page 6 of 8

\begin{tabular}{|c|c|c|c|c|}
\hline Injection flow capacity & Injection purpose & Purpose of membrane & Type of membranes & Membrane elements \\
\hline $120,000 \mathrm{bpd}$ & $\begin{array}{l}\text { Pressure maintanence for } \\
\text { EOR }\end{array}$ & $\begin{array}{l}\text { Sulphate removal to avoid } \\
\text { barium scaling }\end{array}$ & $\begin{array}{c}\text { FilmTec NF-40 } \\
\text { FilmTec SR-90 } \\
\text { FilmTec SR-90-400 }\end{array}$ & $\begin{array}{l}3 \text { trains, each has } 4 \text { banks with } 12 \text { vessels, each } \\
\text { vessel with } 6 \text { membranes }=864 \text { elements }\end{array}$ \\
\hline
\end{tabular}

Table 2: Brae A, B, C (North Sea) water injection [20].

\begin{tabular}{|c|c|}
\hline NF retentate flow rate $(\mathrm{L} / \mathrm{h})$ & 900 \\
\hline RO permeate flow rate $(\mathrm{L} / \mathrm{h})$ & 50 \\
\hline Water injection flow rate $\left(\mathrm{m}^{3} / \mathrm{h}\right)$ & 108 \\
\hline NF elements required & 120 \\
\hline RO elements required & 2,160 \\
\hline Total cost for NF elements (USD) & 40,200 \\
\hline Total cost for RO elements (USD) & $1,568,160$ \\
\hline
\end{tabular}

Table 3: Membranes required for water injection by NF and RO.

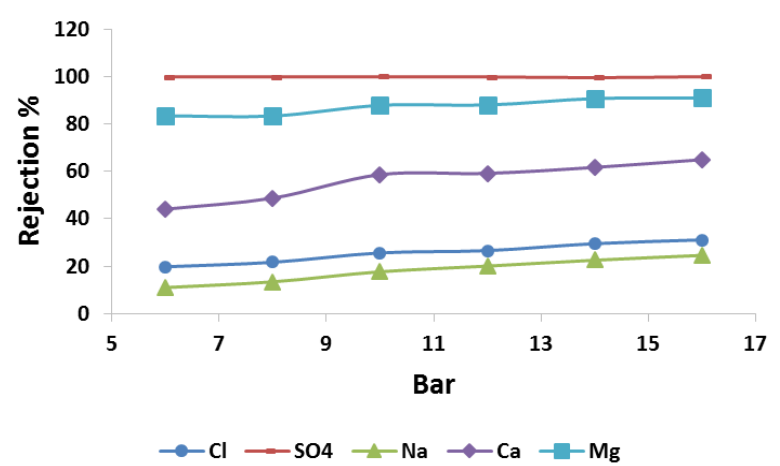

Figure 9: Seawater as feed for NANO SW-2540.
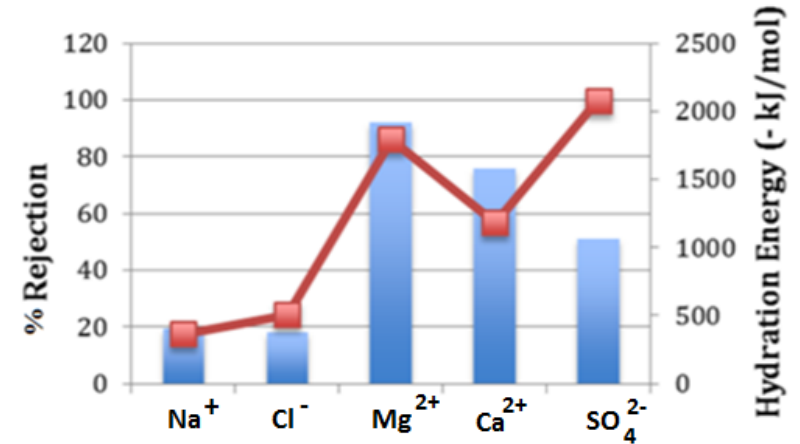

Hydration Energy

Rejection

Figure 10: Relation between hydration energy and rejection of ions at 10 bar.

phosphate chemicals were added separately to feed seawater. Spiking seawater with sulphate and magnesium influenced both the behaviour of ions and membrane separation as shown in Figure 11.

Decreasing rejection of chloride ions: a) Flux decreased as the concentration of $\mathrm{SO}_{4}^{2-}$ in the feed increased.

b) Decrease in flux indicates an increase in resistance, which could be due to membrane pore size reduction (concentration polarization) and / or change in density and viscosity of the solution.
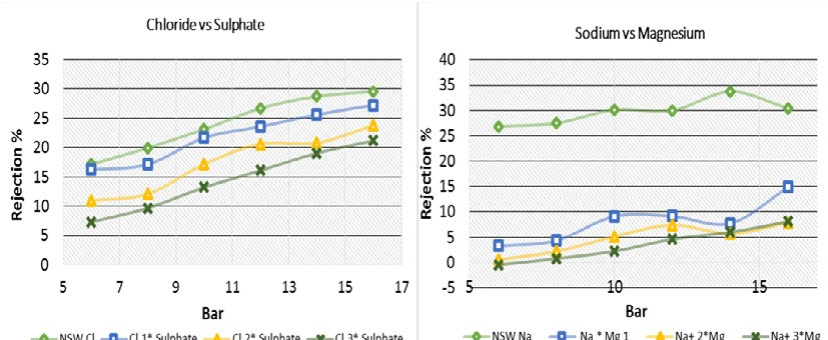

Figure 11: $\mathrm{Cl}^{-}$and $\mathrm{Na}^{+}$rejection with seawater spiked with $\mathrm{SO}_{4}{ }^{2-}$ and $\mathrm{Mg}^{2+}$.

c) A simultaneous increase in sulphate concentration resulted in related decrease in chloride rejection. This phenomenon is shown in Figure 11 and can be explained by Donnan exclusion theory [21]. As concentrations of sulphate were increased, more $\mathrm{Cl}^{-}$passed through the membrane thereby maintaining the charge balance.

Negative rejection of sodium ions: Rejection of sodium decreased dramatically from normal seawater with increasing magnesium spiking. Decrease in rejection for $\mathrm{Na}^{+}$ions for dose 3 at 6 bar and 8 bar is clear from Figure 11.

a. From Table 1 magnesium ions have the highest hydration energy and thus will preferably be rejected at all pressures.

b. Negative rejection is often seen with monovalent ions in the presence of a visible amount of multiple charged ions of the same charge [19]. Decreasing rejection occurs when the concentration of an ion is higher in permeate than in the feed.

c. The concentration of $\mathrm{MgCl}_{2}$ was continuously increased in the feed. To maintain electro neutrality smaller positively charged ion passed through permeate. $\mathrm{Na}^{+}$have a smaller stokes radius and hydration energy than $\mathrm{Mg}^{2+}$ and this favors $\mathrm{Na}^{+}$to permeate through the membrane.

d. A possible explanation is that in charged membranes the singlecharge co-ions replaces the strongly electro-statically excluded multiple-charge ions as in the case of bigger sized magnesium ions to keep the membrane phase electrically neutral [19].

e. Negative rejection of single-charged co-ions were observed only at relatively small permeate flows and turned positive when pressure was increased $[19,20]$.

Monovalent ion rejection: Minimum chloride rejection at a randomly chosen pressure ( 9 bar) were obtained when sulphate and phosphate chemicals were added to the feed. This may be explained by the large sized negatively charged multivalent ions, which are effectively repelled by the negatively charged nanofiltration membrane. Also, in order to maintain electro neutrality, more monovalent ions permeate the membrane. Figure 12 shows that when trivalent phosphate is added to feed seawater, monovalent ion rejection decreased compared with sulphate spiking which is according to Donnan Exclusion $[21,22]$. 
Citation: Nair RR, Protasova E, Bilstad T (2016) Smart Water for Enhanced Oil Recovery by Nano-Filtration. J Pet Environ Biotechnol 7: 273. doi:10.4172/2157-7463.1000273

\section{Smart water formulation}

Measured TDS concentrations in retentate was high throughout the experiments. TDS in retentate increased in all cases of spiking and is mainly due to the increase in feed TDS and high flux with loss of "pure" water to permeate.

In order to overcome high TDS in retentate, three dilution options were considered. Most efficient combinations for smart water production are:

a) NF retentate and RO membrane permeate.

b) NF retentate with Multi-flash distillation (MSFD) of seawater.

c) NF retentate and naturally fresh water.

Whether to choose RO or seawater distillation for diluting TDS was selected after calculating individual power consumption and other costs. Pump Efficiency $\mathrm{n}$ is assumed at $60 \%$. Results of the calculations are presented in Figure 13.

Permeate from RO is mixed with NF retentate to decrease TDS between 10,000 to $28,000 \mathrm{ppm}$ for smart water (Figure 14). Permeate from NF membranes can also be used as feed to RO membranes thereby reducing the quantity of raw seawater used for dilution.

\section{Conclusions}

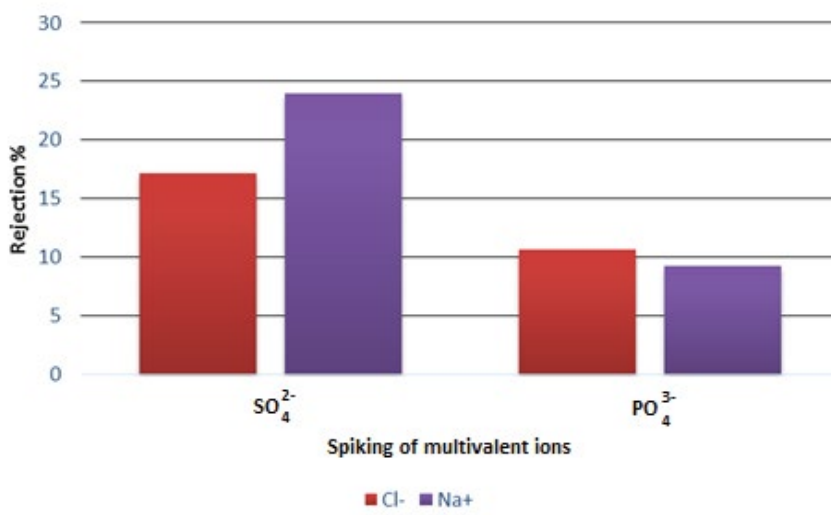

Figure 12: Monovalent ion rejection at 9 bar.

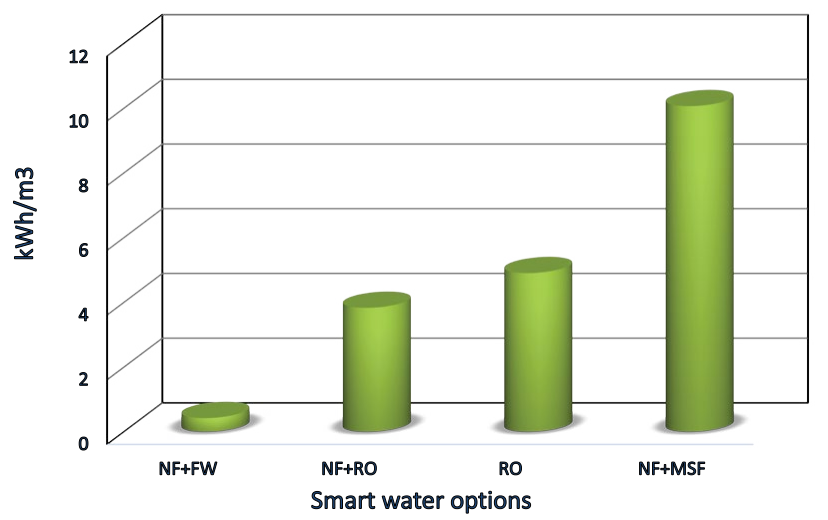

Figure 13: Power consumed by different combinations with NF.

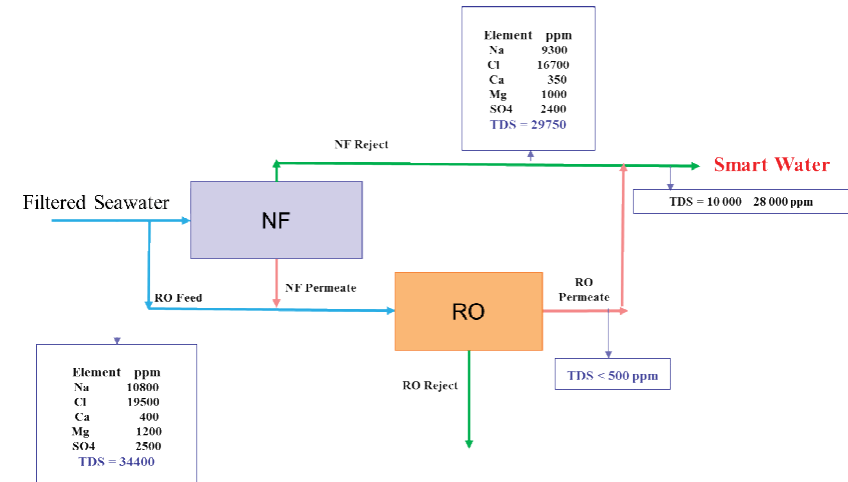

Figure 14: Combination of NF and RO membrane for smart water production

Evaluation of technical and economic factors for smart water production has proven that NF is most efficient with respect to investment and footprint with no added chemicals. Experiments with NF showed that salt rejection increased with feed pressure. Experiments also showed that decreased monovalent ion rejection occurred in the presence of trivalent anion. Decreased rejection was much higher than when feed water was spiked with divalent anions. Economic analysis of smart water production showed that the combination of NF and RO in parallel configuration can be chosen as the universally most economic feasible option when compared to other advanced desalination technologies.

\section{Acknowledgement}

This research has been carried out at University of Stavanger and is financed by the National IOR Centre of Norway.

\section{References}

1. Austad T (2012) Water based EOR in carbonates and Sandstone: New chemical Understanding of the EOR-Potential using "smart water". In: James Sheng (ed.) University of Stavanger, Norway.

2. Stosur G (2003) EOR: Past, present and what the next 25 years may bring Society of Petroleum Engineers.

3. Anderson WG (1986) Wettability Literature Survey-Part 1: Rock/Oil/ Brine Interactions and the Effects of Core Handling on Wettabilty. J Pet Technol 38 11.

4. Fathi JS, Austad T, Strand S (2011) Water-based Enhanced Oil Recovery (EOR) by "smart water": optimal ionic composition for EOR in carbonates. Energy \& Fuels 25: 5173-5179.

5. Kokal S, Al-Kaabi (2010) Enhanced oil recovery: challenges \& opportunities in official publication. EXPEC Advanced Research Centre, Saudi Aramco.

6. Fathi SJ, Austad T, Strand S (2012) Water-based Enhanced Oil Recovery (EOR) by "Smart Water" in Carbonate Reservoirs. Society of Petroleum Engineers, Muscat, Oman.

7. Zhang P, Austad T (2005) Wettability and oil recovery from carbonates: Effects of temperature and potential determining ions. Colloids and Surfaces A: Physicochemical and Engineering Aspects 279: 179-187.

8. Gupta R, Smith G, Hu L, Willingham T, et.al. (2011) Enhanced waterflood for Middle East carbonate cores-impact of injection water composition. Society of Petroleum Engineers, Manama, Bahrain.

9. Carbonate Reservoirs, Schlumberger

10. Heatherly MW, Howell ME, McElhiney JE (1994) Sulphate removal technology for seawater waterflood injection. Offshore Technolgy Conference, Houston, Texas.

11. Cheryan M (1998) Ultrafiltration and Microfiltration Handbook, USA: CRC 
Citation: Nair RR, Protasova E, Bilstad T (2016) Smart Water for Enhanced Oil Recovery by Nano-Filtration. J Pet Environ Biotechnol 7: 273. doi:10.4172/2157-7463.1000273

Page 8 of 8

Press.

12. Childress $A E$, Elimelech $M(2000)$ Relating nanofiltration membrane performance to membrane charge (Electro kinetic) characteristics. Environmental Science and Technology 34: 3710-3716.

13. Manttari M, Pihlajamaki A, Nystrom M (2006) Effect of $\mathrm{pH}$ on hydrophilicity and charge and their effect on the filtration efficiency of NF membranes at different $\mathrm{pH}$. Journal of Membrane Science 280: 311-320.

14. Childress AE, Elimelech M (1996) Effect of solution chemistry on the surface charge of polymeric reverse osmosis and nanofiltration membranes. Journal of membrane science 119: 253-268.

15. Peeters JM, Boom JP, Mulder MV, Strathmann H (1998) Retention measurements of nanofiltration membranes with electrolyte solutions. Journal of membrane science 145: 199-209.

16. Kreig HM, Modise SJ, Keizer K, Neomagus JH (2004) Salt rejection in nanofiltration for single and binary salt mixtures in view of sulphate removal. Desalination 171: 205-215.
17. Richards L, Richards BS, Corry B, Schafer Al (2013) Response to Smith et al.'s comment on experimental energy barriers to anions transporting through nanofiltartion membranes. Environmental Science Technology 47: 8987-8988.

18. Tansel B, Sager J, Garland J, Strayer RF, Levine L, et al. (2005) Significance of hydrated radius and hydration shells on ionic permeability during nanofiltartion in dead end and cross flow modes. Seperation and Purification Technology 51: 40-47.

19. Yaroshchuk AE (2008) Negative rejection of ions in pressure driven membrane processes. Advances in colloid and interface science 139: 150-173.

20. Davis R, Lomax L, Plummer M (1996) Membranes solve north sea water flood sulfate problems. Oil \& Gas Journal.

21. Gawaad RS, Sharma SK, Sambi SS (2011) Comparitive study of Nano and RO membranes for sodium sulphate recovery from industrial wastewater. ARPN Journal of engineering and applied sciences 6: 1-6.

22. Schaep J, Vandecasteele C, Mohammad W, Bowen R (2001) Modeling the retention of ionic components for different Nano-filtration membranes. Separation and Purification Technology 22-23: 169-179. 